\title{
Development of Load Control Algorithm for PV Microgrid
}

\author{
Mohamad Haireen Bin Fatheli ${ }^{1}$, Nur Izzati Zolkifri' ${ }^{2}$ Chin Kim Gan ${ }^{3}$, Musa Bin Yusup Lada \\ ${ }^{1}$ Transmission and International Network Management, Telekom Malaysia, Malaysia \\ ${ }^{1,2,3,4}$ Faculty of Electrical Engineering, UniversitiTeknikal Malaysia Melaka, Malaysia
}

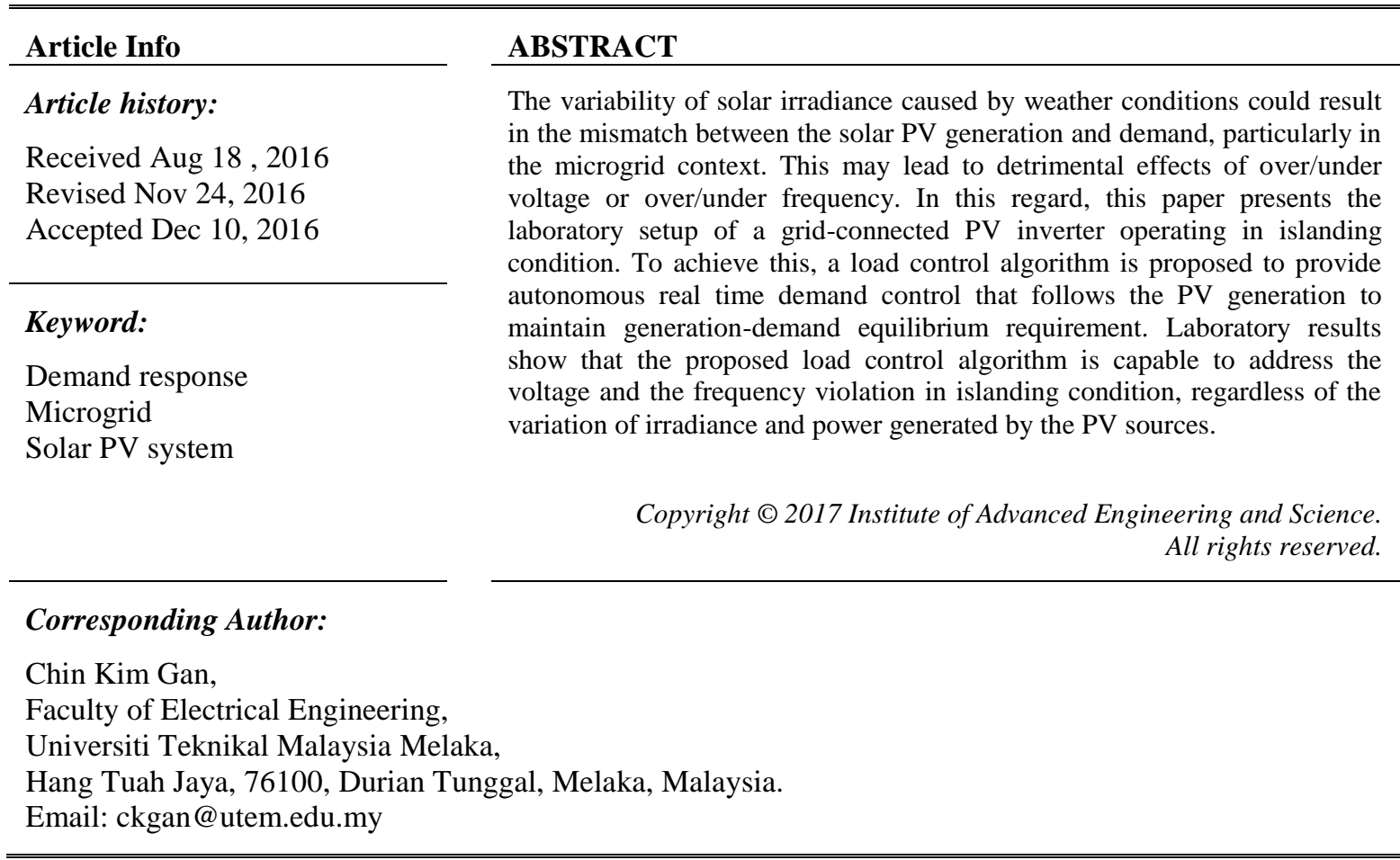

\section{INTRODUCTION}

The demands forelectrical power these few years are increasing, which also see the increase of the use of distributed generation (DG). Energy sources of DGs are divided into two, which are renewable and fossil fuel energy. In order to minimize the utilization of oil and gas as the main source of power generation, numerous researches and studies have been performed these recent years, concentrating on Renewable Energy (RE) as an alternate generation.Renewable Energy Sources (RES), interfaced with power energy conversion and integrated with the loads and energy storage system, enables the RES to serve as a Microgrid that can work in a stand-alone or grid-connected mode operation [1], which makes the microgrid concept become practical. Microgrid is defined as a system that comprises of distributed generation that is interconnected with medium and low voltage distribution system for energy transfer to the grid in gridconnected mode operation [2]. Microgrid offers mutual advantages in the context of the user and utility service provider, while helping in preserving the environment through cleaner energy produced from the RES, which is proven free from any environmental concern. From the user perspective, the establishment of microgrid through the grid interface connection promises improvement on the network quality by providing reactive and harmonic compensation [3], as well as reducing the impact of pollution to the environment and the cost to the user through an incentive scheme introduced by the local energy commissions.

Photovoltaic (PV) generation is one of the popular renewable energies. Solar energy is inexhaustible and effective to generate bulk supplies of electricity. However, PV generation type depends on the weather condition, which implies the output power is not constant all the time. The introduction of PV grid-tie inverter helps to overcome the constant output issue by providing integration of the PV power output with utility in a grid system, compensating each other [4]. The role of grid-tie inverter is to convert the DC supply or non-asynchronous supply into synchronous AC supply of voltages that could smoothly or easily 
interconnect with the utility supply [5]. Moreover, in grid interconnected mode, the inverter serves as a current source to provide preset power to the grid [6].

PV grid-tie inverter is designed with an anti-islanding mode that prevents power from the inverter being transmitted to the grid when the grid is disconnected. As a consequence, local load will be interrupted indiscriminately, which incurs unnecessary outage following the grid outage [7]. Hence, the optimization of energy is not fully utilized though the source is ready and available. The islanding offers a solution to this problem through intentional islanding that allows the inverter to be working, supplying the power to the local loads in this mode. However, the intentional islanding has a drawback, in which the solar energy fluctuates over time, depending on the weather condition. Voltage and frequency in intentional islanding are risky in the wake of the uncertainty of the PV supply. With regard to this, in this paper, a load control algorithm system is presented in this paper, designed to address voltage and frequency stabilization issue, and further to compensate the uncertain energy produced by the PV supply. The load control algorithm will serve as a load management that follows generation, to provide protection to the local loads and PV system, respectively. LABVIEW software has been incorporated with the Data Acquisition (DAQ) devices in this experiment to measure the current and voltages of the PV and load system.

\section{RESEARCH METHOD}

\subsection{Sunny Boy 2000 HF-US Grid-Tie PV Inverter}

The Sunny Boy 2000 HFS-US is a PV inverter system which functions to convert direct current (DC) of a PV array into alternating current (AC), to feed into the power distribution grid. The PV inverter system operates on a load that resonates at $50 \mathrm{~Hz}$ frequency, which matches the output of the PV inverter perfectly. Due to the safety design, the Sunny Boy PV inverter is incorporates withan anti-islanding protection algorithm system to prevent the PV inverter from transporting the supply when the grid is disconnected. The Sunny Boy PV inverter will inject periodically both leading and lagging reactive current in this anti-islanding algorithm to destabilize and de-energize from a balance islanding condition.

Although reconfiguration of the Sunny Boy PV inverter into the islanding is prevented automatically in-system, it still can be configured to the islanding externally. The fundamental of the Sunny Boy PV inverter operation is by having the load to resonate at $50 \mathrm{~Hz}$ frequency to match the PV inverter output [8]. Injecting an external AC source with $50 \mathrm{~Hz}$ frequency to the load until the source signal is matched to the PV output will allow the Sunny Boy PV inverter to work in islanding mode. In this experiment, reconfiguration into the islanding mode was conducted by isolating the grid supply manually. A reference signal from the external source was injected to the PCC until the signal matched the output of the Sunny Boy PV inverter. Then, the Sunny Boy PV inverter could be configured to an intentional islanding mode [9].

\subsection{Point of Common Coupling (PCC)}

PCC in this experiment provided a common point for the PV inverter and utility supply to synchronize. The PCC functioned as a base of the access point for direct measurement between these two supplies. The PCC was designed with the circuit breaker protection, to prevent over-current fault from damaging the system [10]. Terminal Blocks were attached to the DIN-Rail and mounted on the board to provide accessibility to the source which was interfaced in the PCC. The PCC electrical diagram is shown in Figure 1(a). The hardware implementation is shown in Figure 1(b).

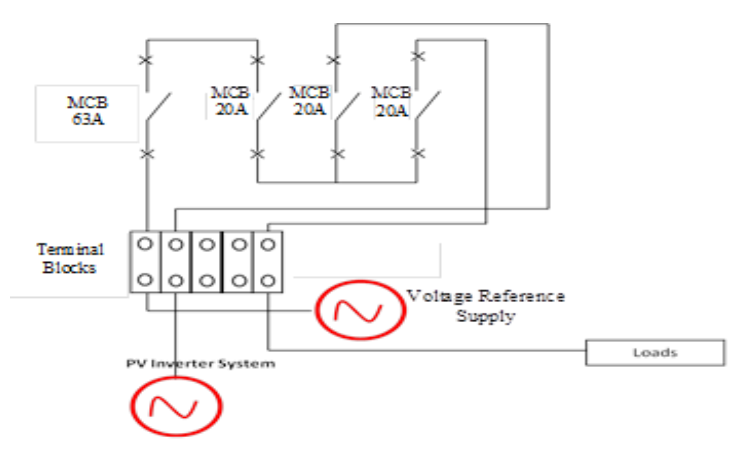

(a)

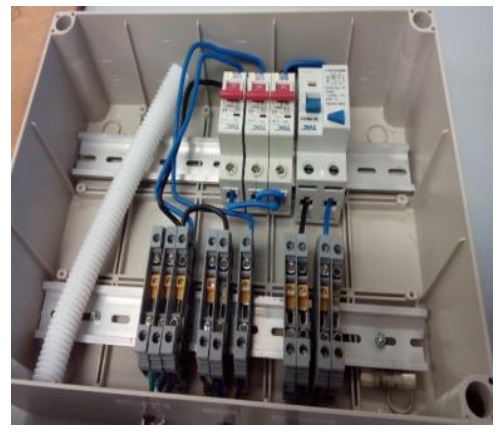

(b)

Figure 1. (a) PCC electrical diagram, (b) PCC hardware implementation 


\subsection{Isolation Transformer}

Isolation transformer was employed in this experiment to isolate the output neutral of the PV inverter system from the voltage source supply, where the voltage source supply served as a reference signal in intentional islanding mode. The PV inverter and reference voltage supply were merged together in the PCC board in an intentional islanding environment. Whenever two sources merged together, there would be twoneutral inputs and a single output neutral connection, as illustrated in Figure 2(a). This led to the problem of how to connect a single output neutral, given with two inputs neutral at the same time.

Combining these two sources does not require their neutrals to be connected together. Connecting the inputs neutral together to the output neutral can create circulating current between the input neutrals, as shown in Figure 2(b), which can be hazardous if two inputs neutral come from the different sources. An isolation transformer placed in series at one of the sources should provide the solution to this problem. The isolation transformer serves as a medium to electrically separate one of the neutral input wires coming from the two different sources. As a result, only one input neutral wire is connected to the output neutral wire directly. In this experiment, neutral input from the voltage source was electrically separated using the isolation transformer, which enabled the neutral input from the PV inverter system to be connected directly to the output neutral to the load.

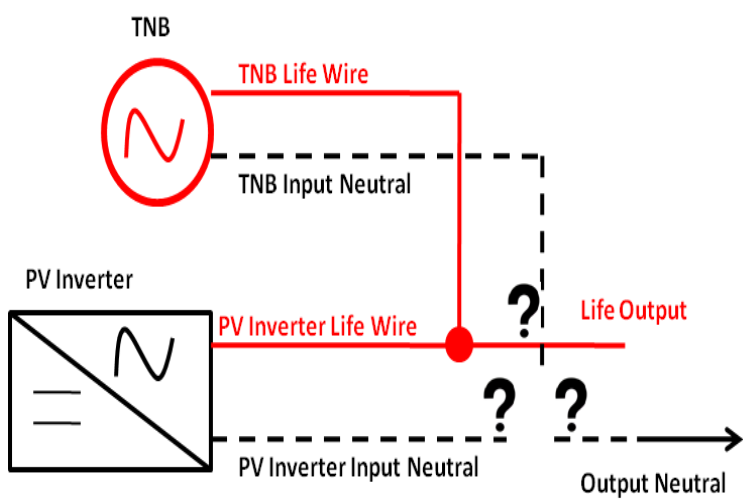

(a)

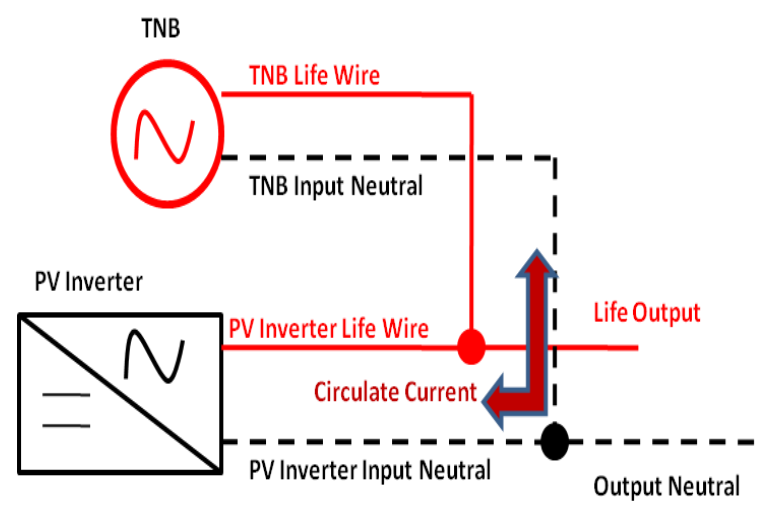

(b)

Figure 2. (a) Two inputs neutral and a single output neutral, (b) Circulate current between inputs neutral

\subsection{Load Bank}

Constant load at $1000 \mathrm{~W}$ single phase was set in this experiment with the intention to observe the effects of the fluctuating PV supply to the constant loads. Three-phase load bank was utilized in this experiment and the load was recalculated to be set in this load bank accordingly. This was because the load required in this experiment should be in a single phase while the load bank utilized was a three phase load system.

The load bank utilized in this experiment had a balance load whose phase impedances were equal in magnitude and phase. The resistance value of the load bank is given in wattage (W). As the load was balanced in a three-phase load bank, conversion of three-phase loadinto the single phase load was done as in Equation 1:

$$
\mathrm{P}_{\text {load } 1 \varnothing}=\frac{\text { Pload } 3 \emptyset}{3}
$$

\subsection{Development of Load Control Algorithm Software}

Development of a load control algorithm system is divided into two, which are software design, that acts as a brain to the load control algorithm, and hardware implementation, that demonstrates the effectiveness of the load algorithm. The algorithm flow chart is developed as guidance to the software development. Figure 3 below shows the algorithm flow chart developed for this load control system.

The algorithm flowchart in Figure 3 starts with the measurement of the current from PV inveter and the load system. The algorithm program is developed to activate subject to the PV energy availability and will be placed to off immediately once the PV energy has diminished. Then, the PV current is compared to the load current. If the PV current is higher than the load current and meets the time delay set at respective 
individual load, the load will be connected sequentially. However, if the PV current is lower than the current load in turn, the algorithm flow chart will measure the difference between the load current and the PV current, respectively. The difference of the value is then compared with the threshold value. If the difference current is greater than the threshold value given, load will be shed accordingly, or else the amount of the load will be retained as it has been connected. The algorithm is a continuous process as long as PV energy is present. LABVIEW software is incorporated with the Data Acquisition (DAQ) devices to measure the current and voltages of the PV and load system.

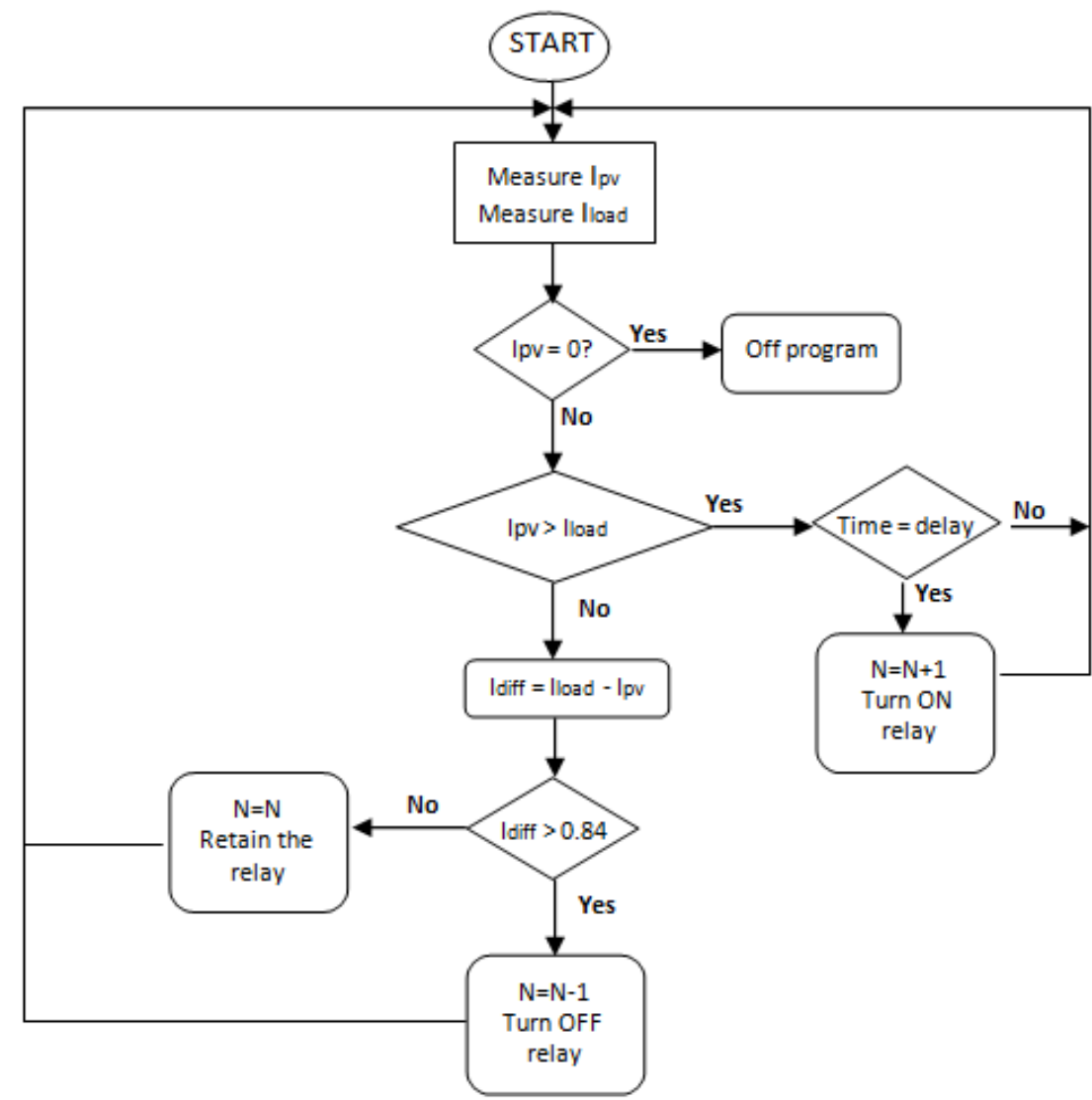

Figure 3. Algorithm flow chart for load control system

A single channel configuration with a complete load control algorithm system for the experimental setup is shown in Figure 4. DAQ Assistant is utilized as a single simulated device to measure three parameters in the live system, namely, PCC Voltage, PV current and load current, respectively. Select Signals VI is employed in this software configuration to split up the three parameters measured using a single DAQ Assistant. 


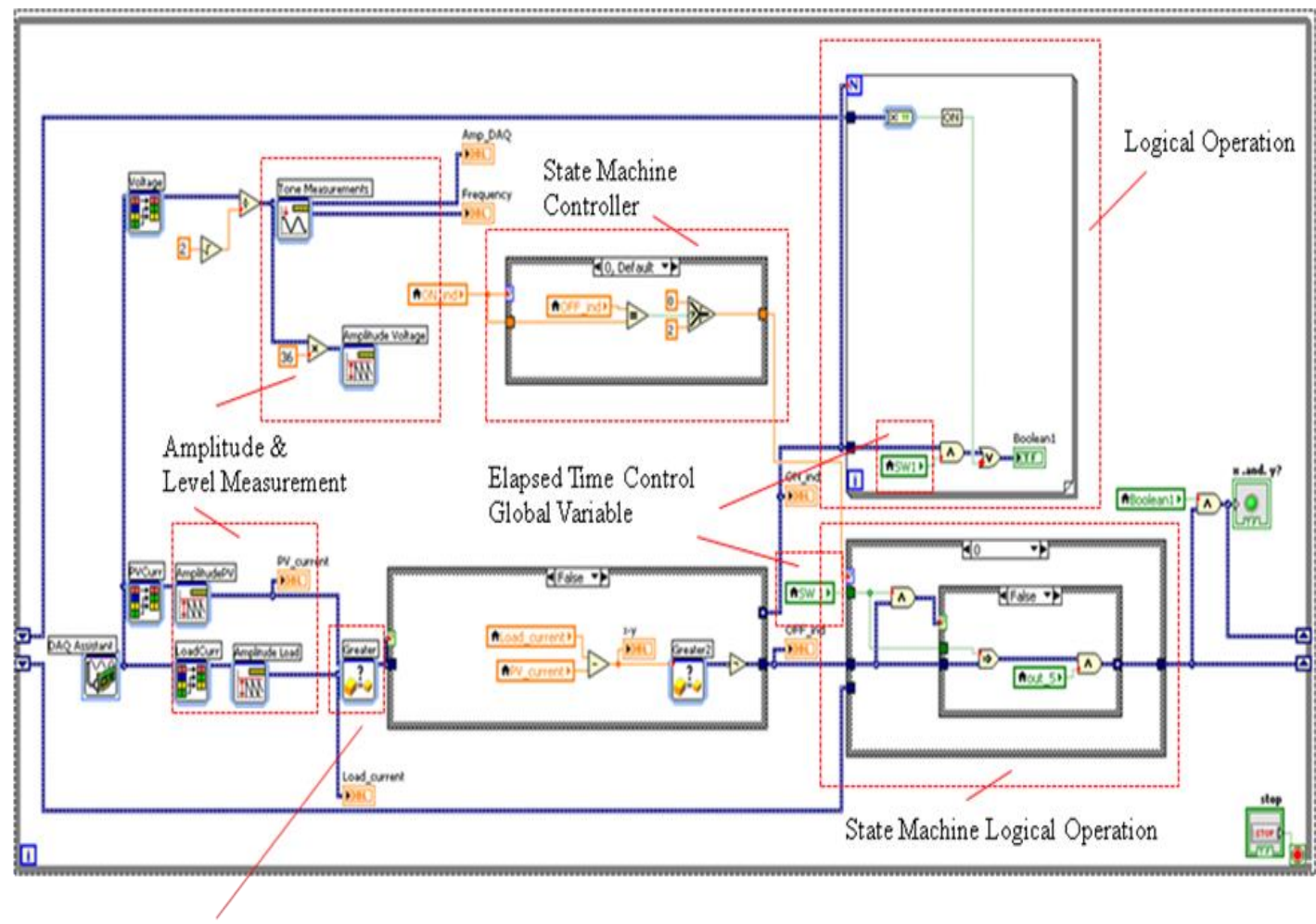

Current Comparison

Figure 4. Single channel of load control algorithm system

The hardware devices for load control algorithm system are listed in Table 1, which include the Point of Common Coupling (PCC) with the circuit breakers protection, isolation transformer, low voltage (LV) step-down transformer, transducer, relay switching modules, National Instrument Data Acquisition (NI DAQ), DC-DC converter, Buffer circuit, and LABVIEW programming, which all form a complete load control algorithm system.

Figure 5 shows the load control algorithm block diagram established for this project.

Table 1. Hardware components for load control algorithm system

\begin{tabular}{|c|c|c|c|}
\hline No. & Hardware components & Rating/Model & Quantity \\
\hline 1 & Isolation Transformer & $240 / 240 \mathrm{~V}$ & 1 \\
\hline 2 & LV step down transformer & $240 / 6 \mathrm{~V}$ & 1 \\
\hline 3 & Current Transducer & $15 \mathrm{~V}, 20 \mathrm{~A}, \mathrm{LEM}$ HY 20-P & 2 \\
\hline 4 & Relay Switching Module & $5 \mathrm{~V}, 8$-channel Relay Interface Board, $15-20 \mathrm{~mA}$ Driver Current & 2 \\
\hline 5 & Relay Switching Module & 5V, 4-channel Relay Interface Board, 15-20mA Driver Current & 1 \\
\hline 6 & NI compact DAQ Ethernet chassis & NI 9181 & 4 \\
\hline 7 & Digital Output Module & NI 9472 & 3 \\
\hline 8 & Analog Voltage Input Module & NI 9205 & 1 \\
\hline 9 & NI Managed Ethernet Switch & NI - MES 3980 & 1 \\
\hline 10 & Buffer Circuit & $20 \times 1 \mathrm{k} \Omega$ resistance circuit & 1 \\
\hline 11 & DC-DC Converter & $1 \mathrm{~A}, 12 / 5 \mathrm{~V}$ & 1 \\
\hline 12 & AC/DC Enclosed Switching Dual Power Supply & $10 \mathrm{~A}, 240 \mathrm{Vac} / 12 \mathrm{Vdc}$ & 1 \\
\hline
\end{tabular}




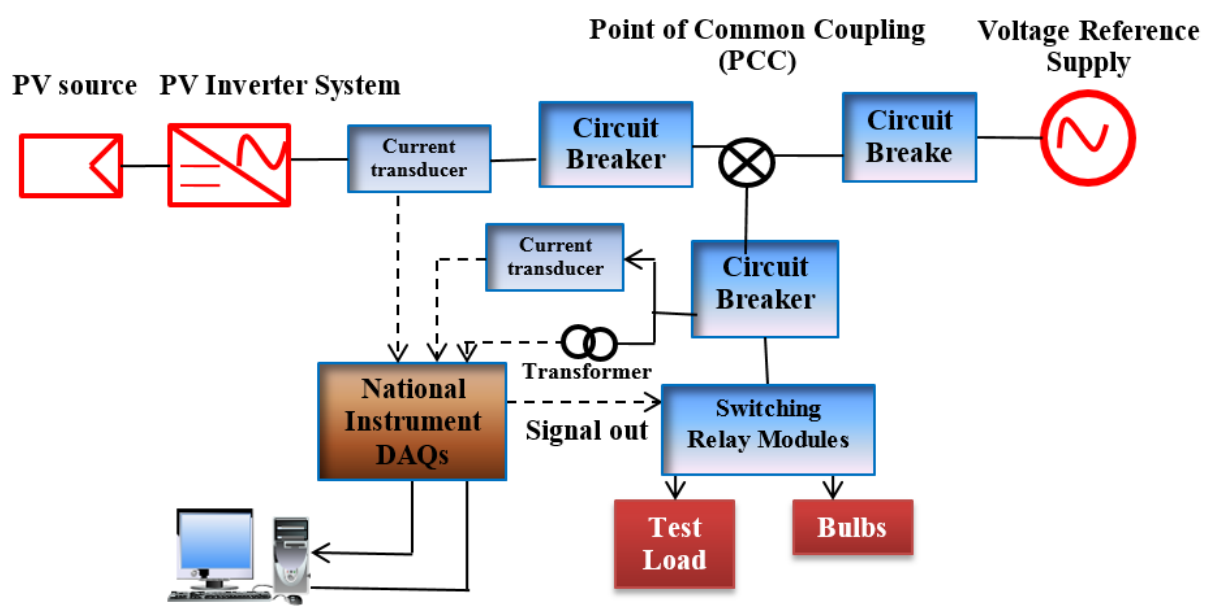

LABVIEW monitoring, processing and controlling

Figure 5. Load control algorithm block diagram

\subsubsection{LABVIEW Software Load Control Algorithm}

In this experiment, LABVIEW software was incorporated with the Data Acquisition (DAQ) devices to measure the currents and voltages of the PV and load system. The measured parameters data were then transferred to the control application design in the LABVIEW code, to process the inputs following the designated algorithm software and generate digital output signals to trigger the relay function of a load control system. LABVIEW software has two panel architectures, namely the front panel and the block diagram panel. The front panel serves to define the algorithm interface, which in this experiment functioned to monitor the software interface and measured parameters.

Figure 6 shows the front panel of the LABVIEW software.

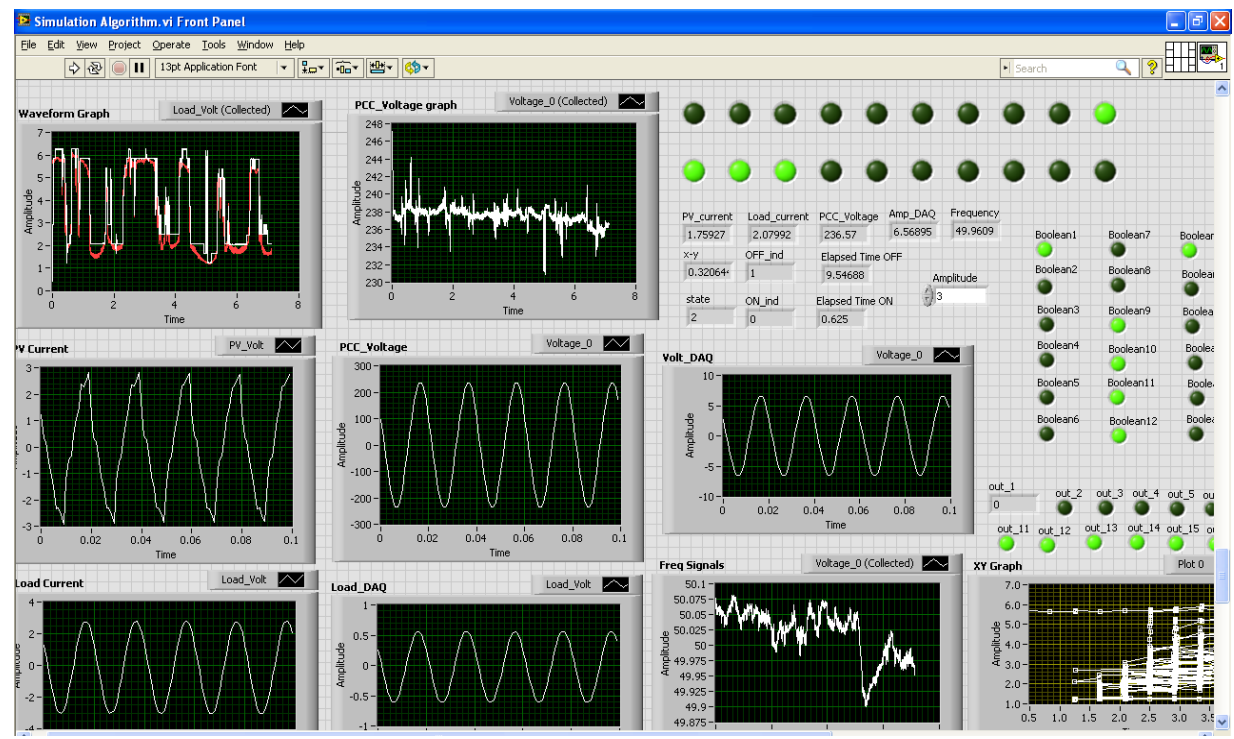

Figure 6. Front panel of LABVIEW software

\subsection{Experimental Setup}

The actual experimental was carried out by configuring the PV inverter system operating in the islanding mode. To ensure the transition of the grid connected to the islanding mode be successful, a load bank was utilized to match the output generated by the PV system, while waiting the load algorithm system to initiate. Otherwise, the transition would not be successful while conducting experiment at the peak output 
of the PV system. Figure 7 shows the hardware experimental setup. The novelty of this experimental setup is that the configuration allows the grid-tie inverter to operate in islanding mode with the source of reference voltage. For simplicity, we considered the utility as the reference voltage, which can be replaced by other tupes of AC power source.

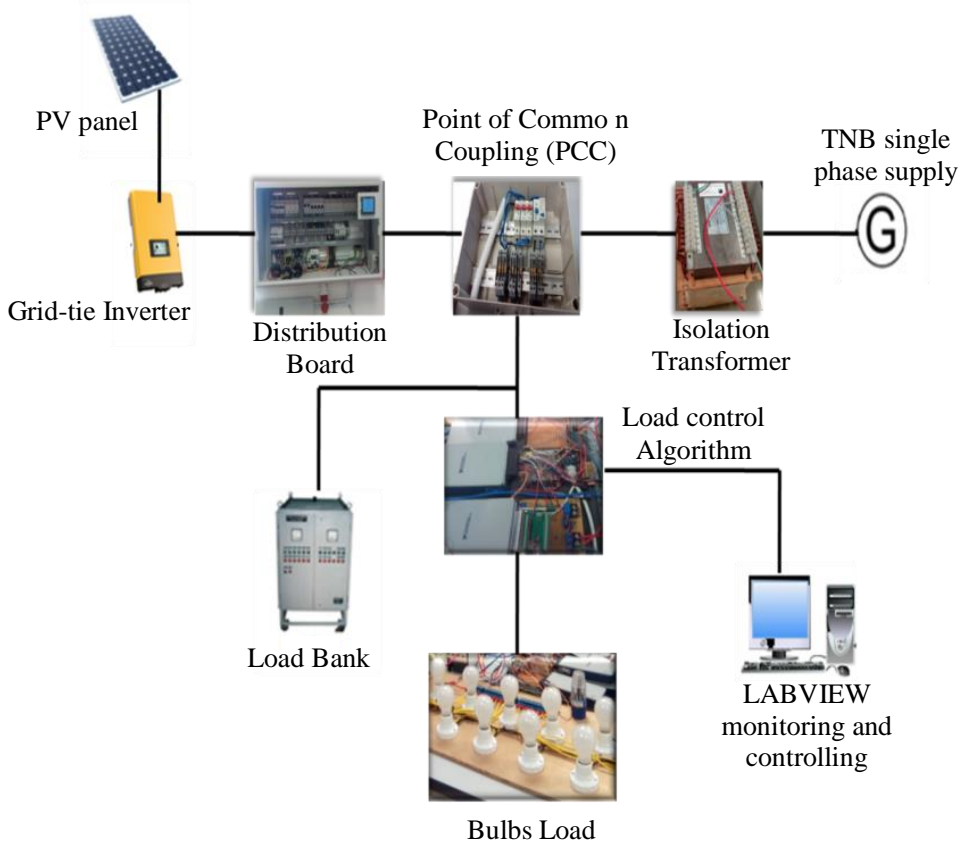

Figure 7. Hardware experimental setup

\section{RESULTS AND ANALYSIS}

\subsection{Intentional - Islanding With the Load Control Algorithm System}

The load control algorithm is a designated system that controls the amount of the load to be connected corresponding to the PV generation level. The load control algorithm system monitors the magnitude of current delivered to the load, and controls the energy balance between the PV generation and load demand respectively.

\subsubsection{Load Demand Follow the PV Generation}

PV inverter current and load current are two parameters which were monitored and controlled in this algorithm design. The load current was designed to follow the PV current, as shown in Figure 8. Load demand parallel with generation was successfully established in the actual system test operating in islanding mode, producing load current corresponding to PV current change.

The algorithm design managed to control the load amount according to the PV generation level by controlling the load current which continuously followed the PV current all the time. However, at certain operation cycle, it was found that the load current encountered fluctuation for a few seconds before resuming normal operation. Fluctuations occurred due to the hardware timing of data acquisition (DAQ) that was not synchronized with the software timing. Never the less, the fluctuation could be minimized by introducing time delay to the software program.

As a result of the mismatch of the software and hardware timing, fluctuation occurred since the relay switching module was supplied with intermittent signal from the DAQ modules. Furthermore, the DAQ modules permitted the relay operation to intermittently operate until the mismatch between the software and hardware timing was rectified through self synchronization on these two timings accordingly. The load current was higher in the graph presented, as a sign to prevent reverse current from propagating into the external voltage source. The load was slightly higher from the PV current designed in the algorithm as a security assurance to prevent reverse power flow from occurring. Regardless of the intermittent of the PV supply, the load could be controlled for the amount of the PV supply generated. Unlike microgrid 
experimental setup using solar power emulator [11], actual working PV system with real connected loads was considered in this work.

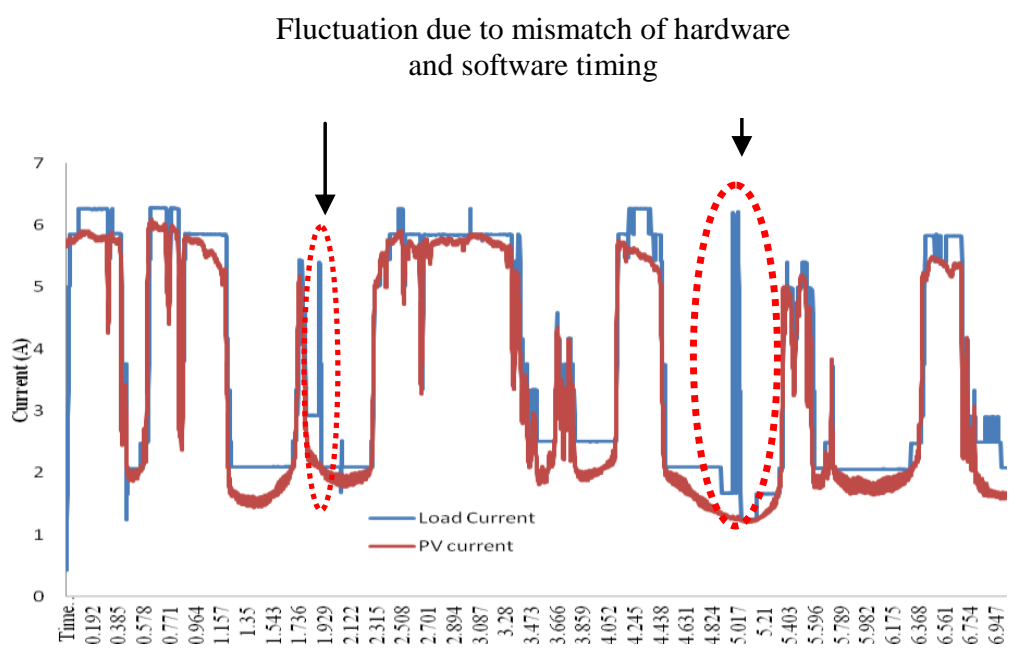

Figure 8. Load current follow PV current generation

\subsubsection{Voltage Stability Offered by Load Control System}

Figure 9 shows the load voltage measured in islanding mode with the load control algorithm system. The voltage can be briefly described as with the load control system, the load voltage was observed operating in $+10 \%,-6 \%$ voltage limit [12] and free from any voltage violation in islanding.

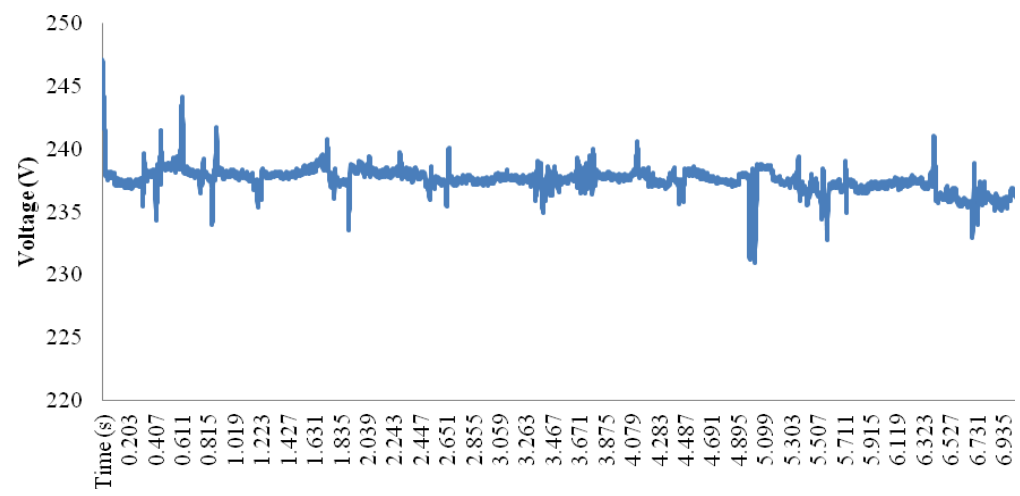

Figure 9. Load voltage operating in islanding with load control system

Figure 10 shows irradiance as a variable parameter. The fluctuation of irradiance energy was due to the weather and global sun position, which implies that the PV source is not a constant type of energy, thus posing reliability issues in power generation [13].

The irradiance energy was then transformed into DC input of the PV inverter, where the energy conversion output was in AC waveform, as shown in Figure 11. The AC voltage declined excessively at the beginning of the operational cycle because the transition from grid was disconnected to the islanding mode. Nevertheless, the DC voltage could be kept constant, mainly due to the Maximum Power Point Tracking (MPPT) that maximized the power output in event of irradiance fluctuation.

The AC voltage successfully controlled working at voltage limit, free from any voltage violence. In spite of fluctuation due to weather variances affecting the input PV inverter, which was unmanageable by the MPPT, the voltage could still be retained as constant due to the aids of the load control algorithm system. Hence, the PV inverter current source proves fit to workin islanding environment. 


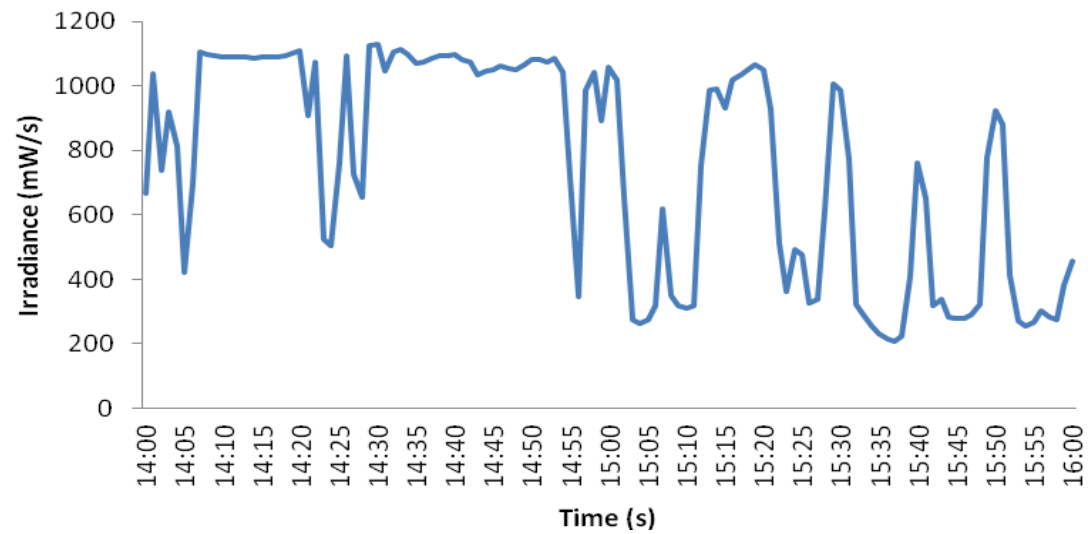

Figure 10. Irradiance data

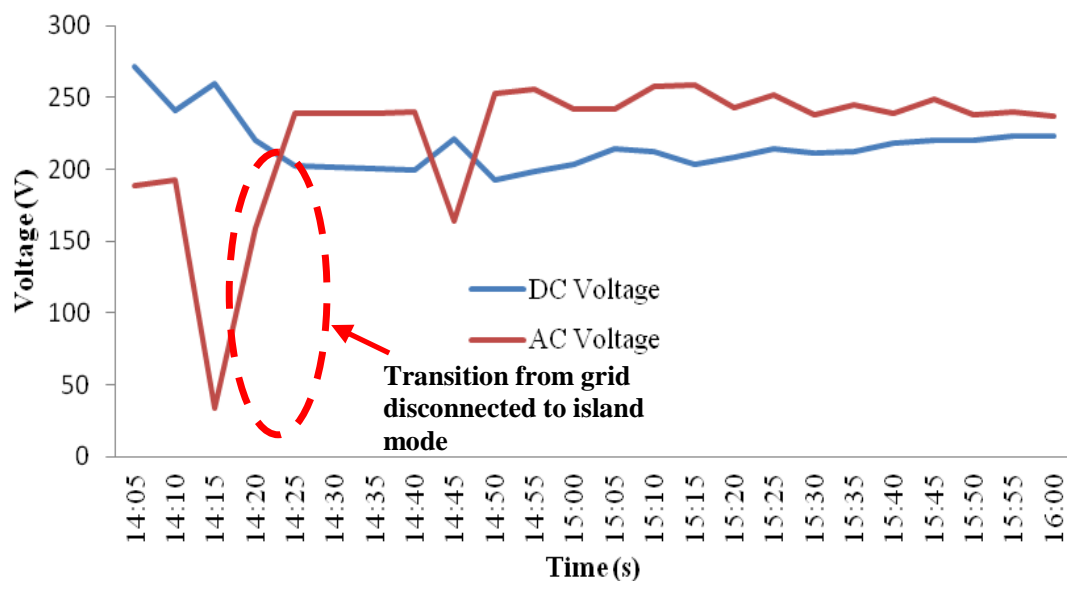

Figure 11. DC and AC voltage PV inverter system

\subsubsection{Frequency Stability Offered by Load Control System}

Figure 12 shows the load frequency showing with the load control algorithm system, in which frequency was operated in limit from $49.5 \mathrm{~Hz}$ to $50.5 \mathrm{~Hz}$ [14] and immune from any gradual changes in the course of unreliable source provided by the PV system in islanding.

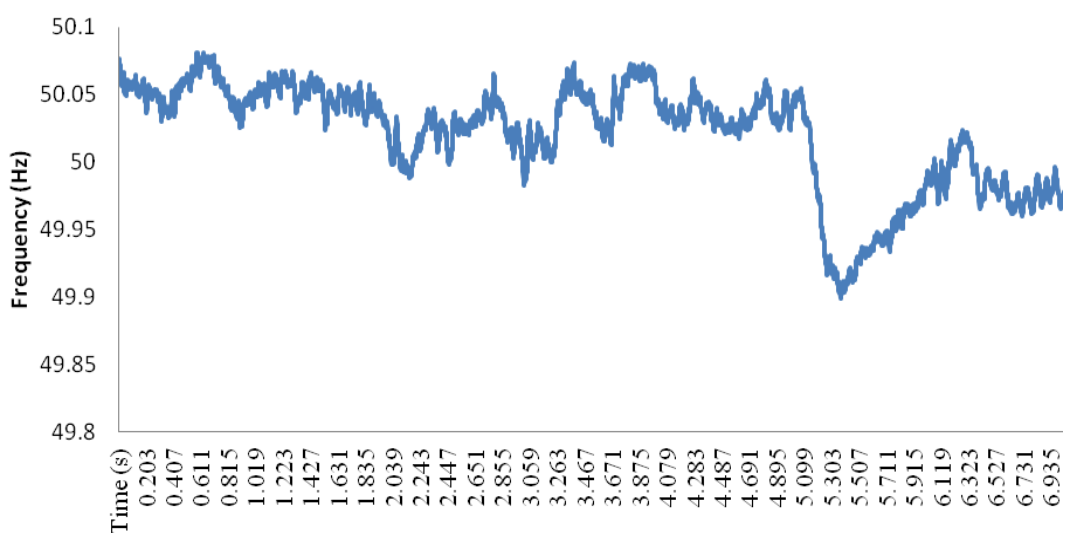

Figure 12. Load frequency measured 


\subsection{PV Inverter Current Distortion}

The measured PV inverter current and the load current are shown in Figure 13. It was observed that the inverter current waveform was in a form of distorted signal, while the load current waveform was purely in sinusoidal from.

The degree of distortion was due to the harmonic presence, showed when significant distorted signal was encountered and when low PV supply was generated to the load. At this time, the PV inverter operated with low power conversion where the distortion was very high [15] [16]. The external voltage source in turn, provided the necessary current that mixed up with the distorted current from the PV inverter, producing pure sinusoidal waveform to the load. Thus, power quality was preserved in good quality to the load.

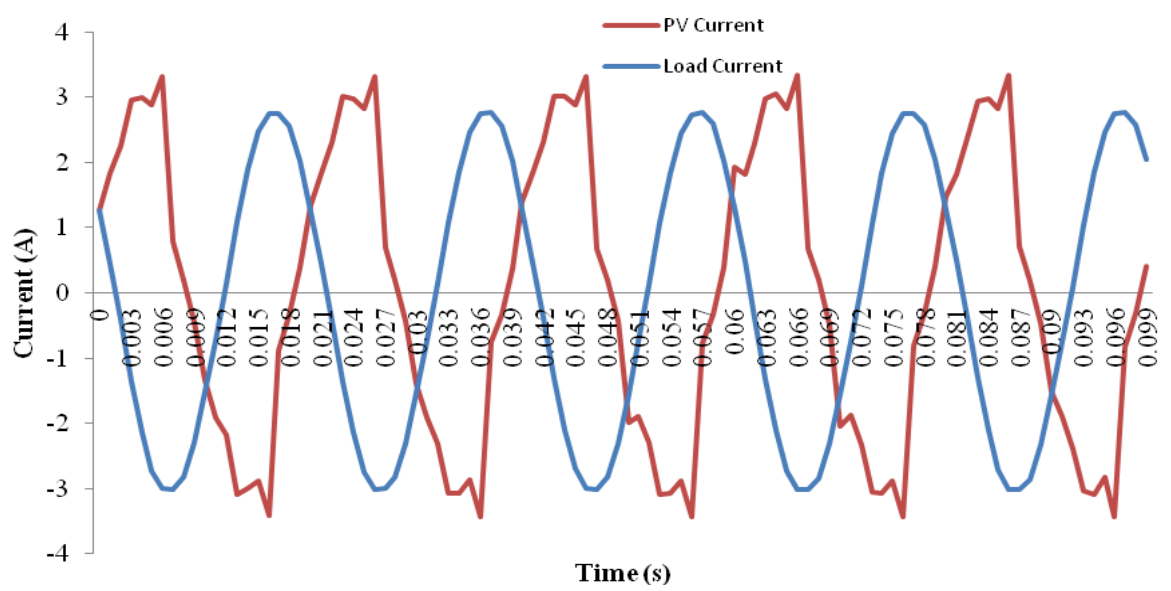

Figure 13. PV inverter current and load current

Figure 14 shows the irradiance data against temperature, showing that distorted signal appeared at low irradiance, proportional to the low panel temperature. The relation shows that when temperature rises, the irradiance will rise as well [17]. As such, the inverter would have problems producing good power quality if it had worked as a standalone system. The function of external voltage in this experiment was to ensure good power quality be delivered to the load, providing compensation to the distorted signal at the time of the irradiance energy being low.

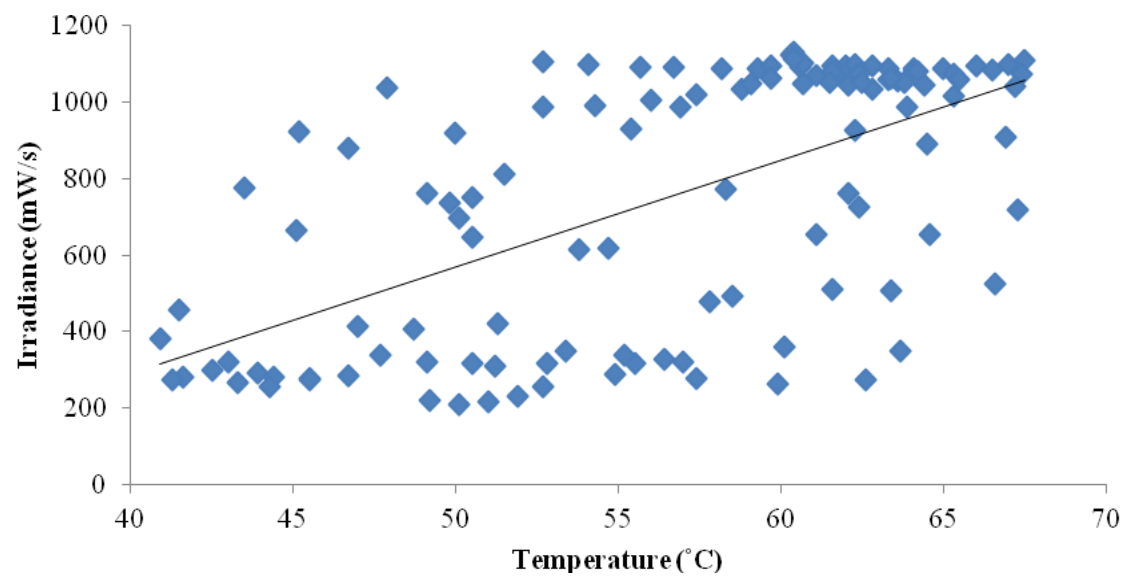

Figure 14. Irradiance versus temperature

The results showed that the load current followed the PV current continuously all the time until the PV supply was dismissed. The voltage was constantly stable at the point of PCC, as the load was connected based on the PV generation level, which prevented any over-voltage or under-voltage scenario from 
occurring. Hence, the load control algorithm system, instead of addressing the stability issue in the intentional islanding from the context of voltage and frequency, also provided protection from over-voltage or under-voltage to the load and PV supply at the same time. It has been proven that the load control algorithm system can effectively control the load in actual test of grid connected PV system for PV microgrid restoration, which is in line with the objective of this paper.

\section{CONCLUSION}

Variability of solar irradiance due to weather condition could result in the mismatch between solar PV generation and demand, particularly in the microgrid context. This may lead to detrimental effects of over/under voltage or over/under frequency. As proven in this study, the developed load control algorithm is able to accommodate PV generation operating in intentional-islanding mode. The load control algorithm system will maintain demand-supply in a balance condition, by usinga switch relay control that connects the loads according to the PV generation level. The load control algorithm system has been successfully designed using LABVIEW software to form a complete and autonomous load control algorithm system to control the load presence in accordance to the PV generation.

\section{ACKNOWLEDGEMENTS}

The authors gratefully acknowledge the financial support provided by the Ministry of Higher Education Malaysia under the Research Grant: RAGS/1/2015/TK03/FKE/03/B00096. Special appreciation and gratitude are expressed to the Center of Robotics and Industrial Automation (CeRIA), Centre of Research and Innovation Management (CRIM) and Faculty of Electrical Engineering (FKE) ofUTeM for giving the financial and moral support forsuccessful completion of this project.

\section{REFERENCES}

[1] Barnes, M., Dimeas, A., Engler, A., Fitzer, C., Hatziargryriou, N., Papathanassiou, S., Vandenbergh, M., 2005, "Microgrid laboratory facilities", International Conference on Future Power Systems, pp. 1-6.

[2] Trujillio Rodriguez, C., Velasco de la Fuente, D., Garcera, G., Figueres, E., Guacaneme Moreno, J.A., 2013, "Reconfigurable Control Scheme for a PV Microinverter Working in Both Grid-Connected and Island Modes", IEEE Transactions on Industrial Electronics, 60(4), pp 1582-1595.

[3] Dall'Anese, E., and Gianakis, G.B., 2014, "Risk-Constrained Microgrid Reconfiguration Using Group Sparsity", IEEE Transactions on Sustainable Energy, 5(4), pp. 1415-1425.

[4] Hartono, B.S., Budiyanto, Y., Setiabudy, R., 2013, "Review of Microgrid Technology”, International Conference on QiR (Quality in Research), pp. 127-132.

[5] IEEE.Standards-1547.2, 2008. IEEE Application Guide for IEEE STD 1547TM, IEEE Standard for Interconnecting Distributed Resources with Electric Power Systems. IEEE Standards Coordinating Committee 21. [Online] Available from: http://ieeexplore.ieee.org/xpls/abs_all.jsp?arnumber=4816078 [Accessed: 12 December 2014].

[6] Wandhare, R.G., Thale, S., Agarwal, V., 2014, "Design of Photovoltaic Power Conditioning System for Hierarchical Control of a Microgri”, IEEE 40th Photovoltaic Specialist Conference (PVSC), pp 3144-3149.

[7] M. Shamshiri, C. K. Gan and Chee Wei Tan, "A review of recent development in smart grid and micro-grid laboratories," Power Engineering and Optimization Conference (PEOCO) Melaka, Malaysia, 2012 IEEE International, Melaka, 2012, pp. 367-372.

[8] Guo, Xiao-Qiang., Wu, Wei-Yang., Gu, He-Rong., 2011, "Phase Locked Loop and Synchronization Methods for Grid-Interfaced Converters: A Review", [Online] Available at: www.red.pe.org.pl/articles/2011/4/48.pdf [Accessed on 12 February 2014]

[9] Kotsopoulos, A., Duarte, J.L., Hendrix, M.A.M., Heskes, P.J.M., 2002, "Islanding behaviour of grid connected PV inverters operating under different control schemes", IEEE 33rd Power Electronics Specialists Conference, 2002, 2002(3), pp. 1506-1511.

[10] ALLEN-BRADLEY-CB. Application, 1994. Using Circuit Breakers to Protect Transformer Circuits. ALLENBRADLEY.

[11] R.R. Islam, M. Liao, T.H. Vo and J. Ravishankar, "Experimental setup of a microgrid with wind and solar power emulators," Electrical Energy Systems (ICEES), 2014 IEEE 2nd International Conference on, Chennai, 2014, pp. 914.

[12] Tenaga Nasional Berhad, "Electricity Supply Application Handbook", 3rd ed. 2011. [Online] https://www.tnb.com.my/assets/files/ESAHv3.pdf]

[13] Afroze, S., Udaykumar, R.Y., Naik, A., 2012, “A Systematic Approach to Grid Connected PV system”, IEEE 5th Power India Conference, pp. 1-5.

[14] Johari, A., 2010. The Malaysian Grid Code. [Online]. 2010. Available from: http://www.tnb.com.my/tnb/application/uploads/uploaded/the Malaysian grid code.pdf. 
[15] Hamid, M.I., and Jusoh, A., 2014, "Reduction of Waveform Distortion in Grid-Injection Current from Single Phase Utility Interactive PV-Inverter", Energy Conversion and Management, pp. 212-226.

[16] M. Ayub, C.K. Gan and A.F.A. Kadir, "The impact of grid-connected PV systems on Harmonic Distortion," 2014 IEEE Innovative Smart Grid Technologies - Asia (ISGT ASIA), Kuala Lumpur, 2014, pp. 669-674.

[17] Anonymous, 2010, "Coordinated Control Scheme for Standalone PV System with Nonlinear Load", IEEE PES Transmission and Distribution Conference and Exposition, pp. 1-8.

[18] M. Abdulkadir, A.S. Samosir, A.H.M. Yatim, 2013, "Modeling and Simulation of Solar Photovoltaic System, Its Dynamics and Transient Characteristics in LABVIEW", International Journal of Power Electronics and Drive System (IJPEDS), pp. 185-192.

[19] Himanshu Sharma, Nitai Pal, Yaduvir Singh, Pradip Kumar Sadhu, 2015, "Development nd Simulation of Stand Alone Photovoltaic Model Using Matlab/Simulink", International Journal of Power Electronics and Drive System (IJPEDS), Vol.6, No. 4, pp. 703-711.

[20] Yafaoui, A., Bin Wu, Kouro, S., 2012, "Improved Active Frequency Drift Anti-islanding Detection Method for Grid Connected Photovoltaic Systems", IEEE Transactions on Power Electronics, 27(5), pp. 2367-2375.

[21] Xin Chen., Yan Hong Wan., Yun Cheng Wang., 2013, "A Novel Seamless Transferring Control Method for Microgrid Based on Master-Slave Configuration.”,2013 IEEE ECCE Asia Downunder (ECCE Asia) 2013, pp. 351-357.

[22] Liu Jie, Yang Haizhu, 2009, “Anti-Islanding Control of Grid Connected Photovoltaic Inverter Based on Positive Feedback Frequency Drift", IEEE 6th International Power Electronics and Motion Control Conference, pp. 2147-2150. 